\title{
Historic trends in ocean acidification on coral reefs revealed by laser ablation MC-ICPMS analysis of coral $\delta^{11} \mathbf{B}$
}

\author{
CHRISTOPHER D STANDISH ${ }^{1}$, DR. THOMAS B CHALK ${ }^{2}$ \\ AND GAVIN L FOSTER ${ }^{2}$ \\ ${ }^{1}$ Ocean \& Earth Sciences, University of Southampton \\ ${ }^{2}$ University of Southampton \\ Presenting Author: gavin.foster@noc.soton.ac.uk
}

Around $1 / 3$ of all anthropogenic $\mathrm{CO}_{2}$ emissions have been absorbed by the ocean. This has led to a decrease in ocean $\mathrm{pH}$ by approximately $0.1 \mathrm{pH}$ units, and around a $30 \%$ decline in dissolved carbonate ion concentrations. The latter in particular is thought to have a negative impact on coral calcification by lowering the saturation state of aragonite (the polymorph of $\mathrm{CaCO}_{3}$ corals build their skeletons from). However, due to a number of biogeochemical processes (e.g. calcification, organic carbon production) the carbonate system on the reef is not the same as the open ocean, with reef $\mathrm{pH}$ determined instead largely by the balance between net ecosystem calcification (NCC) and net ecosystem productivity (NPP). This, coupled with a general lack of geochemical monitoring on reefs stretching back beyond the last decade, makes the impact of ocean acidification on tropical corals difficult to assess.

Here we will use a recently developed analytical technique (laser ablation multicollector inductively coupled plasma mass spectrometry) to examine the boron isotopic composition $\left(\mathrm{d}^{11} \mathrm{~B}\right)$ and boron content $(\mathrm{B} / \mathrm{Ca})$ of coral skeletons recovered from several regions around the globe (Bermuda, Hawaii). These regions were chosen as they are places where decade-long openocean carbonate system monitoring (e.g. at BATS and HOTS) as well as local reef monitoring have been performed (e.g. https://www.pmel.noaa.gov/co2/story/Hog+Reef). We focus here on whether the very high-spatial resolution available with the laser ablation technique (equating to weekly or better temporal resolution) enables seasonally resolved reconstructions of reef $\mathrm{pH}$. By overlapping with intervals of local monitoring we are able to assess the role of coral vital effects relating to biomineralisation vs. variations in reef biogeochemistry in driving the observed $\mathrm{pH}$ trends. Unpicking the relative importance of these processes in driving the observed variations in $\mathrm{d}^{11} \mathrm{~B}$ and $\mathrm{B} / \mathrm{Ca}$ is a challenge, but is essential if the geochemistry of coral skeletons is to be used to reliably reconstruct the carbonate system on reefs beyond the reach of our instrumental record. 